\title{
Realistic Dilemma and Solution of "Vocational Skill Test" under the Background of Enrollment Reform of Classified Examination in Higher Vocational Colleges in Jilin Province
}

\begin{abstract}
Guoxun Zheng ${ }^{*}$, Liang Zhao ${ }^{2}$, Ruojin Wang 3 , Chengming Wang ${ }^{4}$
${ }^{1}$ Science and Technology Research Division, Changchun Institute of Technology, Changchun, China

2Secondary Education Enrollment and Examination Department, Education Examinations Authority, Changchun, China

${ }^{3}$ Enrollment and Employment Division, Jilin Communications Polytechnic, Changchun, China

${ }^{4}$ Secondary Education Enrollment and Examination Department; Higher Education Enrollment and Examination Department, Education Examinations Authority, Changchun, China

*Corresponding author: Guoxun Zheng, cc_zgx1982@163.com

Abstract: In the process of Higher Vocational classified examination enrollment reform, Jilin Province has adopted a diversified examination enrollment model and "cultural quality test + vocational skill test" evaluation method, and established the "vocational education college entrance examination" system. This paper analyzes the important role and practical difficulties of "vocational skill test" in Higher Vocational classified examination, studies the existing problems, and puts forward to reasonably divide the proportion of "cultural quality test" and "vocational skill test", sets diversified admission standards, scientifically sets up the assessment methods and contents of "vocational skill test", further improves the "cultural quality test + vocational skill test" evaluation method and builds a classified examination and enrollment system more in line with the characteristics of vocational education.
\end{abstract}

Keywords: Classified enrollment in higher vocational colleges; Vocational skill test; Vocational education; Multiple admission criteria

Publication date: December 2021; Online publication: December 27, 2021

\section{Introduction}

In 2019, the State Council proposed to establish the "vocational education college entrance examination" system in the national vocational education reform implementation plan, which Improved the examination and enrollment method of "cultural quality + vocational skills," improved the quality of students, and provided students with a variety of admission and learning methods for receiving higher vocational education. ${ }^{[1]}$ The national policy documents put forward clear requirements for classified enrollment in higher vocational colleges. In the process of classified examination reform in higher vocational colleges, all provinces should improve the enrollment, admission mode and training system, focus on selecting and training high-tech skilled talents urgently needed for industrial transformation, alleviate the employment pressure and serve our country's economic development. 
2. Background of enrollment reform of classified examination in higher vocational education in Jilin Province

\subsection{Development period of classified examination and enrollment in higher vocational colleges}

In 2016, under the guidance of relevant documents of the Ministry of education, Jilin Province formulated the plan for deepening the reform of examination and enrollment system in Jilin Province, which aims to promote the reform of classified examination and enrollment system in higher vocational education, explore the selection and examination method of "cultural quality + vocational skills," and build a diversified enrollment and assessment method of classified examination in higher vocational education.

From 2015 to 2018, the higher vocational enrollment in Jilin province gradually formed enrollment modes such as ordinary college entrance examination, single enrollment in higher vocational education, counterpart enrollment and connection between secondary and higher vocational education. The enrollment forms of classified examination in higher vocational education are more diversified. The enrollment of Higher Vocational Colleges in Jilin Province is increasing. By 2018, the number of single enrollment and counterpart enrollment of Higher Vocational Colleges in Jilin province accounted for more than $60 \%$ of the total number of Higher Vocational candidates, while the proportion of candidates admitted through the ordinary college entrance examination has decreased year by year. The classified enrollment examination of higher vocational colleges has become the main channel of higher vocational college enrollment.

\subsection{The mature period of classified examination enrollment in higher vocational colleges}

In 2019, Jilin Province issued the regulations of Jilin Province on enrollment in 2019 higher vocational classified examination, emphasizing the improvement of Higher Vocational classified examination methods. At present, the enrollment modes of Higher Vocational Colleges in Jilin Province mainly include ordinary college entrance examination for ordinary high school graduates, single enrollment in higher vocational colleges, counterpart enrollment for secondary vocational graduates, transition from secondary and higher vocational education to higher education and five year higher vocational education.

After the introduction of the "million enrollment expansion" special plan in 2019, the enrollment of Higher Vocational classified examination in Jilin Province has increased the higher vocational enrollment expansion examination for migrant workers, new professional farmers, grass-roots agricultural technicians, veterans and laid-off unemployed. Candidates do not need to participate in the cultural quality examination, but directly participate in the "vocational skill test" organized by higher vocational colleges.

Jilin Province has initially formed the "vocational education college entrance examination" system. With its advantages of diversity, inclusiveness and fairness, the classified examination of higher vocational colleges has become the main way of enrollment of higher vocational colleges in Jilin Province, and trained more high-tech and skilled talents for the country. All these show that the enrollment reform of classified examination of Higher Vocational Colleges in Jilin Province has made good progress.

\section{The realistic dilemma of "vocational skill test"}

The comprehensive development of higher vocational classified examination enrollment has promoted the higher vocational education in Jilin Province to enter a new stage of development. At the same time, the problems existing in the higher vocational classified enrollment examination have gradually emerged, such as the enrollment plan cannot meet the needs of candidates, the specialty setting of higher vocational colleges is unreasonable, etc. Among them, the dilemma faced by the "vocational skill test" examination is particularly prominent. 


\subsection{The important role of "vocational skill test"}

As our country enters the late stage of industrialization, economic and social development and industrial structure upgrading need a large number of high-tech skilled talents, which puts forward new requirements for talent structure, so that more young people can realize their life value by virtue of their skills. Higher vocational education will play a more important role in the economic transformation of large countries. Therefore, Jilin Province should speed up the construction of a modern vocational education system, build a skilled society, carry forward the craftsman spirit, and cultivate more high-quality technical and skilled talents, skilled craftsmen and craftsmen from large countries, so as to provide strong talent and skill support for the comprehensive construction of a socialist modern country ${ }^{[2]}$.

In the single entrance examination of higher vocational colleges in Jilin Province, candidates who have reached the qualification line of "vocational skill test" will participate in the "vocational skill test" organized by higher vocational colleges. The candidates of the "million enrollment expansion" special plan directly participate in the "vocational skill test" organized by higher vocational colleges. "Vocational skill test" is an important link for higher vocational colleges to select and cultivate high-tech skilled talents. Organizing "vocational skill test" is an important premise and guarantee for selecting high-quality students and realizing the purpose of vocational education.

\subsection{The proportional relationship between "cultural quality test" and "vocational skill test" is not harmonious}

The source of candidates in higher vocational classified examination is complex, so we should be comprehensive and reasonable in the process of examination proposition. However, the proportion of "vocational skill test" is lower than that of "cultural quality test" in the current vocational single enrollment model for ordinary high school graduates and the counterpart enrollment model for secondary vocational graduates in Jilin Province. If the examinee's "cultural quality test" does not reach the qualification line of "vocational skill test," he will not be able to continue the test. This admission method and the proportion setting of "cultural quality test" and "vocational skill test" will lead to candidates with low cultural literacy and excellent professional and technical skills. Once they fail the cultural quality test, they will lose the opportunity to enter higher vocational colleges for further study, which is not in line with the goal of higher vocational colleges to focus on selecting and cultivating high-tech skilled talents.

\section{3. "Vocational skill test" lacks pertinence to the needs of different students and different majors}

At present, in the process of organizing "vocational skill test," higher vocational colleges do not set corresponding assessment standards for different students. At present, they only conduct assessment according to unified standards, which cannot meet the assessment needs of different types of candidates, especially millions of people. At the same time, the method and content of "vocational skill test" are not scientific enough and are not designed based on professional needs. Higher vocational colleges mostly carry out "vocational skill test" by means of written test or interview, which focuses on theoretical knowledge test rather than practical operation assessment. The test questions have poor correlation with majors, which cannot better reflect the students' vocational skill level.

\section{Solutions to the practical dilemma of "vocational skill test"}

\subsection{Reasonably divide the proportion and set multiple admission standards}

There are differences between the cultural quality level and vocational skill level of different students in the classified examination of higher vocational education. For example, the cultural quality of ordinary high school graduates is relatively high, but the vocational skill test is more difficult for them, while the situation 
of secondary vocational graduates is the opposite. The cultural quality is relatively weak, but the actual operation ability is relatively good. Therefore, secondary vocational graduates should mainly assess vocational skills supplemented by assessing cultural quality. Different admission standards should be set for different students. Among them, the score of "cultural quality test" in Higher Vocational single enrollment test shall not exceed $60 \%$, and the score of "vocational skill test" in counterpart enrollment test shall not be less than 50\%. Through the scientific proportion division, we can effectively solve the problems of emphasizing cultural quality examination and neglecting vocational skill test, so as to meet the needs of the selection of high-tech skilled talents and ensure the scientific, fair and just admission.

\subsection{Scientifically set up the assessment methods and contents of "vocational skill test"}

According to the different source characteristics of ordinary high school graduates and secondary vocational graduates, different assessment methods and contents of "vocational skill test" are set. The "vocational skill test" for high school graduates should measure students' scientific literacy and capacity to innovate, with an emphasis on their fundamental professional quality involved in relevant professional production, service, or management. Professional adaptation test contents, such as professional relevant theoretical knowledge, ideology and moral qualities, can be added to the test material, and the evaluation technique is mostly written test and interview. The old written exam technique for testing professional abilities and practical operating ability should be replaced with a "vocational skill test" for secondary vocational graduates.

\section{Conclusion}

In recent years, Jilin Province has achieved significant success in the enrollment reform of classification examinations in higher vocational education. To resolve the practical dilemma of the "vocational skill test," Jilin Province should fairly divide the proportion of "cultural quality test + vocational skill test" according to the characteristics of different students, set diversified admission standards, scientifically set the assessment methods and contents of "vocational skill test," and further improve the evaluation method of "cultural quality and vocational skill," establish a more scientific, fair, and consistent system.

\section{Funding}

This work was supported by the Social Science Project of the 13th Five-Year Plan of Jilin Provincial Department of Education under Grant no. JJKH20200635SK and the 2019 Vocational Education and Adult Education Teaching Reform Research Project of Jilin Provincial Department of Education under Grant nos. 2019ZCZ067, 2019ZCY413 and 2019ZCY414.

\section{Disclosure statement}

The author declares that there is no conflict of interest.

\section{References}

[1] State Council, 2019, Implementation Plan of National Vocational Education Reform. http://www.gov.cn/zhengce/content/201902/13/content_5365341.htm?from=singlemessage \&isappinstalled $=0$

[2] 2021, The General Office of the CPC Central Committee and The General Office of The State Council Issued the Opinions on Promoting the High-Quality Development of Modern Vocational Education. 
[3] Dong Z, Yuan X, 2017, Exploration of Counterpart Enrollment Reform in Higher Vocational Colleges: Taking Chongqing as an Example. Vocational and Technical Education, (30): 26-29.

[4] Chen J, 2019, Reform of Classified Examination Enrollment in Higher Vocational Colleges: Problems and Strategies. Exploration of Higher Education, (02): 97-102.

[5] Sun H, 2020, Research and Practice of Classification Examination Scheme Design Reform in Higher Vocational Colleges in Jilin Province in The New Era. Science and Technology Information, (04): 106-107.

[6] Dong Z, Yuan X, 2018, Research on Approaches, Problems and Countermeasures of Classified Examination Enrollment in Higher Vocational Colleges. China's Vocational and Technical Education, (02): 5-9. 